\title{
Sobrevivência e viabilidade de escleródios de Botrytis squamosa no solo
}

\author{
Leandro Luiz Marcuzzo $^{1} \oplus$, Mayra Luiza Schelter $^{1} \oplus$
}

\begin{abstract}
${ }^{1}$ Instituto Federal Catarinense - IFC/Campus Rio do Sul, CP 441, CEP 89.163-356, Rio do Sul, SC, Brasil.
Endereço para correspondência: Leandro Luiz Marcuzzo (leandro.marcuzzo@ifc.edu.br)

Data de chegada: 03/01/2018. Aceito para publicação em: 05/02/2019.
\end{abstract}

$10.1590 / 0100-5405 / 192150$

\section{RESUMO}

Marcuzzo, L.L.; Schelter, M.L. Sobrevivência e viabilidade de escleródios de Botrytis squamosa no solo. Summa Phytopathologica, v.45, n.3, p.337-339, 2019.

Em experimento de campo quantificou-se a sobrevivência e a viabilidade de escleródios de Botrytis squamosa no solo. Cem escleródios multiplicados pela técnica de esfregaço de micélio em meio de cultura BDA foram colocados em saquinhos feito de tecido voal. Em armação de madeira contendo solo, colocaram-se 12 repetições respectivamente na superfície e enterrados a 10 centímetros. Mensalmente os saquinhos foram retirados de cada posição, lavados em água corrente e submetidos à compressão com dedo para constatar-se os mesmos mantinham-se intactos. Os escleródios intactos foram submetidos à assepsia com álcool 70\% durante um minuto, hipoclorito de sódio $1,25 \%$ por três minutos e em água estéril para lavagem, em seguida depositado em placas contendo meio BDA e acondicionado em câmara de crescimento a $20^{\circ} \mathrm{C}$ sem luz. Três dias após a incubação realizava-se a contagem dos escleródios germinados. Os escleródios coletados na superfície e enterrados perderam sua viabilidade após oito meses. Os escleródios de $B$. squamosa na superfície tendem a perderem sua viabilidade num período de tempo menor que os enterrados.

Palavras-chave: estrutura de repouso, longevidade, viabilidade.

\section{ABSTRACT}

Marcuzzo, L.L.; Schelter, M.L. Survival and viability of sclerotia from Botrytis squamosa in soil. Summa Phytopathologica, v.45, n.3, p.337$339,2019$.

In a field experiment, the viability of Botrytis squamosa sclerotia in soil was quantified. One hundred sclerotia were multiplied by mycelial smear technique on PDA culture medium and were placed in bags made of voile fabric. In a wooden frame containing soil, 12 replicates were respectively placed on the soil surface and buried at $10 \mathrm{~cm}$ depth. Every month, the bags were removed from each position, washed in tap water and subjected to compression with the finger to check if they were kept intact. Intact sclerotia were sterilized with
$70 \%$ ethanol for one minute, $1.25 \%$ sodium hypochlorite during three minutes and sterile water for washing; then, they were deposited on plates containing PDA culture medium and placed in a growth chamber at $20^{\circ} \mathrm{C}$ without light. Three days after incubation, germinated sclerotia were counted. The collected sclerotia both on the surface and buried lost their viability after eight months. The sclerotia of $B$. squamosa on the surface tend to lose their viability earlier than the buried ones.

Keywords: resting structure, longevity, viability

Botrytis squamosa Walker é o agente causal da doença denominada de queima das pontas que ataca as aliáceas, sendo mais importante na cultura da cebola (Allium cepa L.) (6). Esta doença está amplamente disseminada em regiões de clima temperado, onde são frequentes os períodos de temperaturas amenas $\left(\leq 22^{\circ} \mathrm{C}\right)$ e alta umidade do ar $(\geq$ $90 \%$ ) (10). A doença se manifesta nas folhas por meio de manchas esbranquiçadas, dispostas inicialmente de forma isolada e não esporulante. No entanto, o sintoma característico de maior dano na planta é a queima foliar, ocorrendo do ápice para a base da folha, onde se observa intensa esporulação sobre a parte necrosada da folha (9). A principal fonte primária de inóculo do patógeno são os escleródios e trabalhos ligados a epidemiologia da doença exigem o conhecimento prévio das condições de sobrevivência do inóculo, já que pesquisas relacionadas à queima das pontas no Brasil ainda são escassas.

A referência sobre a biologia de sobrevivência de escleródios de B. squamosa cita que esses podem sobreviver por mais de 21 meses (2), mas sem detalhes desta sobrevivência ao longo do tempo até a sua viabilidade final. Mediante a este aspecto, o objetivo desse trabalho foi avaliar a sobrevivência e a viabilidade de escleródios de $B$. squamosa localizados na superfície e enterrados a $10 \mathrm{~cm}$ da superfície do solo, em condição de pousio.

O experimento foi conduzido no Instituto Federal Catarinense IFC/Campus Rio do Sul, no município de Rio do Sul - SC, (Latitude: $27^{\circ} 11^{\prime} 07^{\prime}$ 'S e Longitude: 49³9'39' W, altitude 655 metros) durante o período de doze meses (abril de 2017 a março de 2018). A temperatura média do ar foi de 17,$6 ; 16,4 ; 14,2 ; 14,2 ; 14,8 ; 18,0 ; 17,8 ; 18,6$ e $21,8^{\circ} \mathrm{C}$ e a precipitação de $107 ; 330 ; 137 ; 27 ; 159 ; 65 ; 161 ; 187$ e $174 \mathrm{~mm}$, respectivamente, durante os meses de abril de 2017 a dezembro de 2017 em que foram constatados os escleródios intactos e viáveis no solo.

Foi utilizado isolado de $B$. squamosa obtido da coleta de conídios sobre o tecido foliar lesionado de mudas de cebola e multiplicado por sete dias em câmara de crescimento do tipo B.O.D (Demanda Biológica de Oxigênio) a $20^{\circ} \mathrm{C}$ e sem luz em placas de Petri contendo meio de cultura BDA (Batata-Dextrose-Ágar) sem antibiótico. Os escleródios foram produzidos pela técnica de esfregaço sobre o micélio com o auxílio de um pincel de pintura $\left(\mathrm{n}^{\circ} 8\right)$ e após as placas foram incubadas 
por 15 dias em B.O.D a $20^{\circ} \mathrm{C}(7)$.

Após a multiplicação, foi realizado o teste de avaliação de sobrevivência, onde 100 escleródios foram colocados dentro de saquinhos $(10 \times 4 \mathrm{~cm})$ confeccionados de tecido voal e amarrados na extremidade com arame flexível encampado para não haver perdas de escleródios $(4,5)$.

Os saquinhos com os escleródios foram depositados a campo protegidos lateralmente em uma armação de madeira de $1 \mathrm{~m}^{2}$ com 0,2 $\mathrm{m}$ de profundidade contendo solo, onde 12 saquinhos foram depositados na superfície e 12 enterrados a 10 centímetros de profundidade no solo. O solo utilizado foi um Cambissolo Háplico, com os seguintes atributos químicos: pH em água de 6,0; matéria orgânica de $2,8 \%$; teores de $\mathrm{Ca}^{+2}$, $\mathrm{Mg}^{+2}, \mathrm{Al}^{+3}$ e CTC de 4,2; 1,8; 0,0 e 9,54 cmolc. $\mathrm{dm}^{-3}$, respectivamente; saturação por bases de $66,49 \%$, teor de argila de $30 \%$ e teores de P e $\mathrm{K}$ de 14 e $134 \mathrm{mg} \cdot \mathrm{dm}^{-3}$ respectivamente.

Mensalmente foi realizado o teste de sobrevivência dos escleródios, onde foi coletado um saquinho em cada posição no solo. Estes foram lavados em água corrente para remoção do solo aderido e em seguida foram abertos em bancada fazendo a avaliação da rigidez do escleródio através da pressão manual do dedo indicador na superfície da mesa, caso não se desintegrasse era considerado intacto. Os escleródios intactos foram levados para câmara de fluxo laminar e submetidos à assepsia em álcool $70 \%$ por 1 minuto e hipoclorito de sódio $1,25 \%$ por 3 minutos e água estéril para limpeza e foram depositados no máximo dez escleródios em cada placa de Petri contendo BDA sem antibiótico. Posteriormente as placas foram colocadas em B.O.D a $20^{\circ} \mathrm{C}$ no escuro. A viabilidade foi avaliada pela contagem da germinação de escleródios diariamente até o terceiro dia de incubação. Os percentuais de escleródios intactos e viáveis da superfície e enterrados durante os meses avaliados foram ajustados a uma equação polinomial devido ao maior percentual do coeficiente de determinação $\left(R^{2}\right)$.

Os escleródios da superfície tiveram um comportamento com decréscimo no número de escleródios viáveis $\left(\mathrm{y}=0,760 \mathrm{x}^{2}\right.$ $\left.20,20 x+126,8 ; R^{2}=0,935\right)$, sendo que no quinto mês foi onde teve a maior redução da viabilidade dos escleródios, sendo acima de $58 \%$ e que a partir do oitavo mês eles perderam totalmente sua viabilidade (Figura 1). Como os escleródios da superfície estão sujeitos a ciclos de secagem e molhamento acabam germinando antes em comparação com os enterrados. A relação entre escleródios intactos e viáveis foi constante entre os meses, tendo apenas $8 \%$ de diferença na viabilidade no quarto mês e um decréscimo brusco dos viáveis de $89 \%$ do sétimo para o oitavo mês (Figura 1).

Os escleródios intactos coletados foram representados por $y=0,730 x^{2}-19,94 x+127,3 ;\left(R^{2}=0,919\right)$ que permaneceram até o oitavo mês e verificou-se que do nono ao décimo segundo mês nenhum escleródio foi observado no saquinho devido já estarem desintegrados (Figura 1).

A viabilidade dos escleródios enterrados $\left(\mathrm{y}=0,248 \mathrm{x}^{2}-12,19 \mathrm{x}+103,3\right.$; $\left.\mathrm{R}^{2}=0,899\right)$ a $10 \mathrm{~cm}$ de profundidade se estendeu até o oitavo mês (Figura 1). No entanto, dois meses após o inicio do experimento foram registrados os maiores valores de escleródios viáveis concomitante aos intactos com 95 e $88 \%$ respectivamente. A partir do quinto mês, os valores de escleródios viáveis pouco oscilaram (Figura 1), embora o número de escleródios intactos se mostrasse em decréscimo até o oitavo mês, representado pela equação $y=0,231 x^{2}-12,04 x+103,5\left(R^{2}=0,901\right)$. Do oitavo ao décimo segundo mês, apesar de haver poucos escleródios
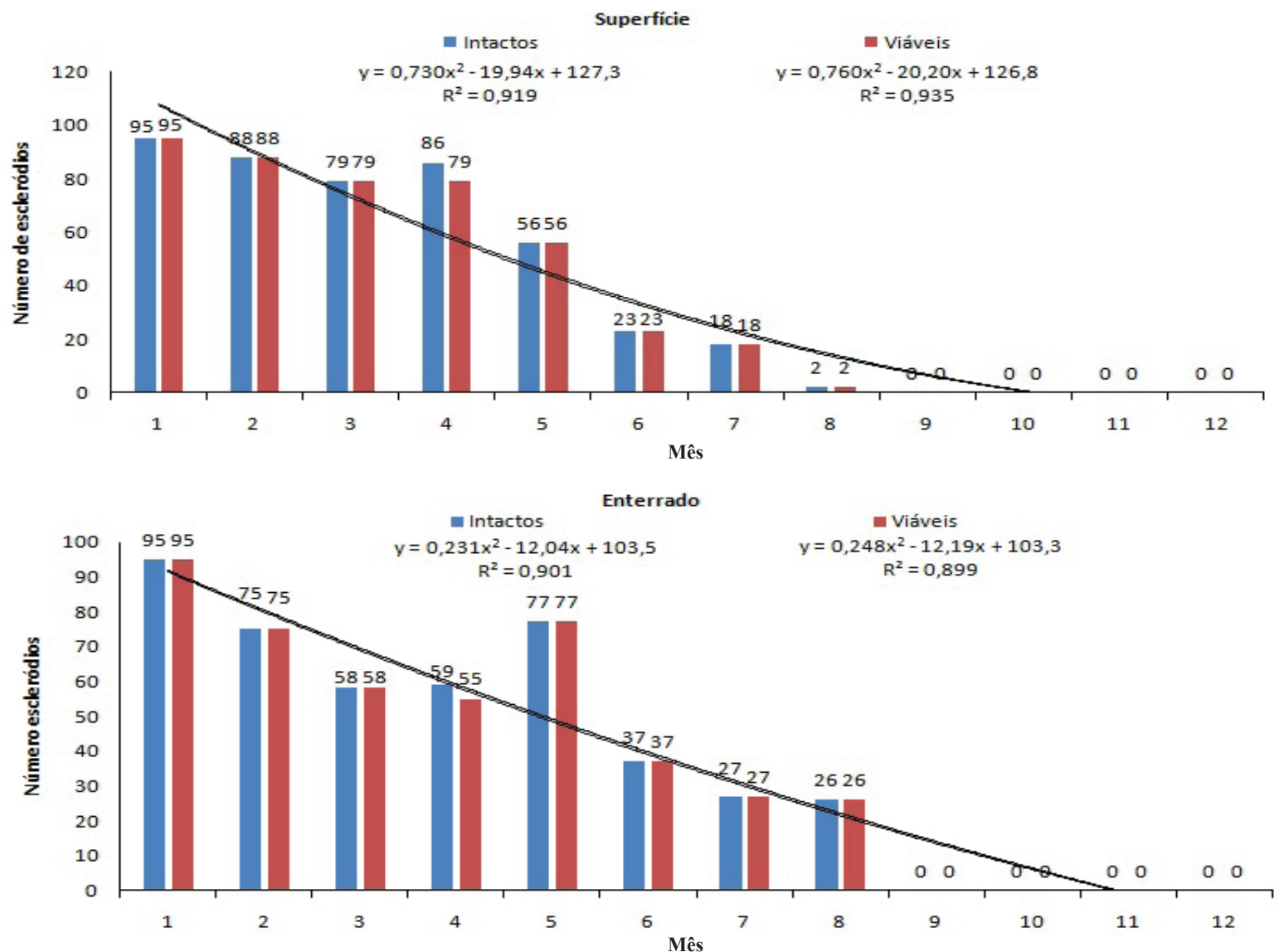

Figura 1. Número de escleródios intactos e viáveis de Botrytis squamosa na superfície e enterrados a $10 \mathrm{~cm}$ no solo. IFC/Campus Rio do Sul, $2017 / 2018$ 
no saquinho, ele desintegrava-se no momento que realizava o teste de pressão com o dedo indicador.

Ellerbrock \& Lorbeer (2) avaliando a sobrevivência de escleródios de $B$. squamosa no estado de Nova York nos Estados Unidos da América, constataram que os escleródios não foram mais recuperados após oito meses na superfície, mas que os enterrados a 3 e $15 \mathrm{~cm}$ foram encontrado mesmo com a finalização do experimento aos 21 meses com 34 e $83 \%$ respectivamente de viabilidade nessas profundidades.

Resultado esse semelhante ao encontrado no presente trabalho, em que a partir dos oito meses os escleródios da superfície não foram mais encontrados (Figura 1). Apesar dos escleródios enterrados apresentarem mesmo tempo de sobrevivência no solo em relação aos da superfície, mas foram encontrados até esse período, possivelmente devido à estabilidade das condições ambientais, já que na superfície do solo estão sujeitos a ciclos de secagem e molhamento e são afetados pela degradação da radiação solar, temperatura e/ou falta de umidade, desta forma germinaram antes dos que foram enterrados (3).

Outro trabalho envolvendo patógeno que forma escleródio foi realizado por Marcuzzo \& Schuller (5) em que avaliando a sobrevivência de escleródios de Sclerotium rolfsii, verificaram que os escleródios enterrados tiveram 15 meses de viabilidade enquanto que os localizados na superfície do solo apenas 9 meses. Já os escleródios de Sclerotium cepivorum coletados na superfície perderam sua viabilidade após três meses e os enterrados permaneceram viáveis até o sétimo mês (2). Brustolin et al. (1) também avaliando a longevidade de escleródios de Sclerotinia sclerotiorum, verificaram que estes perderam sua viabilidade após 12 meses na superfície e de 36 meses quando enterrados no solo (8). Comportamento semelhante foi verificado nesse trabalho, já que os escleródios enterrados permanecem úmidos, fazendo com que tenham uma dormência maior e menor germinação durante os sete meses que permaneceram intactos.

Mediante aos resultados obtidos constatou-se um decréscimo da sobrevivência e viabilidade dos escleródios de B. squamosa, onde da superfície e os enterrados a $10 \mathrm{~cm}$ permaneceram viáveis por apenas oito meses. Portanto, o pousio ou rotação de culturas na cultura da cebola para diminuir consideravelmente o inóculo viável de escleródios de $B$. squamosa, caso seja possível, deve ser de 9 meses.

\section{REFERÊNCIAS}

1. Brustolin, R.; Reis, E.M.; Pedron, L. Longevity of Sclerotinia sclerotiorum sclerotia on the soil surface under field conditions. Summa Phytopathologica, Botucatu, v.42, n.2, p.172-174, 2016.

2. Ellerbrock, L.A.; Lorbeer, J.W. Survival os sclerotia and conidia of Botrytis squamosa. Phytopathology, St. Paul, v.67, n.2, p.219-225, 1977.

3. Ferraz, L.C.L.; Café Filho, A.C.; Nasser, L.C.B.; Azevedo, J. Effects of soil moisture, organic matter and grass mulching on the carpogenic germination of sclerotinia and infection of bean by Sclerotinia sclerotiorum. Plant Pathology, Edinburgh, v.48, n.7, p.77-82, 1999.

4. Marcuzzo, L.L.; Schmoeller, J. Sobrevivencia e viabilidade de escleródios de Sclerotium cepivorum no solo. Summa Phytopathologica, Botucatu, v.43, n.2, p.161-163, 2017.

5. Marcuzzo, L.L.; Schuller, A. Sobrevivência e viabilidade de escleródios de Sclerotium rolfsii no solo. Summa Phytopathologica, Botucatu, v. 40, n.3, p.281-283, 2014.

6. Massola Junior, N.S.; Jesus Junior, W.C.; Kimati, H. Doenças do alho e da cebola. In: Kimati, H.; Amorim, L.; Rezende, J. A. M.; Bergamim Filho, A.; Camargo, L.E.A. Manual de fitopatologia: doenças das plantas cultivadas. 4 ed. São Paulo: Ceres, 2005. v.2, Cap.9, p.53-63.

7. Nascimento, A.; Marcuzzo, L.L. Evaluation of techniques to produce sclerotia of Botrytis squamosa in the middle of culture. In: Congresso brasileiro de microbiologia, 29., 2017, Foz do Iguaçu. Anais. São Paulo: Sociedade brasileira de microbiologia, 2017. Disponível em: $<$ http://www. sbmicrobiologia.org.br/29cbm-anais/listaresumoscongresso.htm $>$. Acesso em: 26 abr. 2018.

8. Reis, E. M.; Tomazini, S. L. Viabilidade de escleródios de Sclerotinia sclerotiorum em duas profundidades de solo. Summa Phytopathologica, Botucatu, v.31, n.3, p.97-99, 2005.

9. Töfoli, J.G.; Ferrari, J.T.; Domingues, R.J.; Nogueira, E.M.C. Botrytis sp. em espécies hortícolas: hospedeiros, sintomas e manejo. Biológico, São Paulo, v.73, n.1, p.11-20, 2011.

10. Wordell Filho, J.A.; Boff, P. queima-acizentada. In: Wordell Filho, J.A.; Rowe, E.; Gonçalves, P.A.; Debarba, J.F.; Boff, P.; Thomazelli, L.F Manejo Fitossanitário na cultura da cebola. Florianópolis: EPAGRI, p.19-30, 2006. 